\title{
ONDATEC: EXPERIÊNCIA INOVADORA COM OS ESTUDANTES DO NONO ANO DO ENSINO FUNDAMENTAL DA REDE MUNICIPAL DE ENSINO DO RECIFE
}

\author{
RECIFE/PE MAIO/2018
}

\author{
Irenice Bezerra da Silva - UniRec - irenicebsilva@gmail.com \\ Rinaldo da Silva Neres - UniRec - rineres@gmail.com \\ Jeane Marta Guedes Aguiar - UniRec - jeanemartaguedes@gmail.com \\ Adriana dos Santos Rodrigues Cavalcanti - UniRec - irenicebsilva@gmail.com \\ Maria Emília Maciel - UniRec - mariaemiliamacieldasilva@gmail.com \\ Claudia de Vasconcelos - UniRec - cacauvcl@gmail.com \\ Sandra Dayse De Albuquerque Ugiette - UniRec - sandraugiette@gmail.com
}

Tipo: Relato de Experiência Inovadora (EI)

Categoria: Pesquisa e Avaliação

Setor Educacional: EDUCAÇÃO CONTINUADA EM GERAL

\begin{abstract}
RESUMO
O presente artigo discorrerá sobre uma experiência inovadora com os estudantes do nono ano do ensino fundamental da Rede Municipal de Ensino do Recife, realizado no ano de 2017 em 36 escolas, denominado OndaTec, com o objetivo de preparar os estudantes para os exames seletivos das Escolas Técnicas Estaduais e Federais de Pernambuco. Descreveremos o passo a passo do Projeto, sua relevância e os resultados obtidos no que concerne ao aumento dos dados estatísticos. Apresentaremos o desenho pedagógico do Projeto, dialogando com os autores sobre a história da educação no Brasil e a contribuição da EaD. Por fim, nas considerações finais enfatizaremos 0 crescimento do percentual de aprovação e o estudo comparativo entre 2016 e 2017 e concluiremos com as perspectivas e expectativas para o Ano 2 da experiência no ano em curso/2018.
\end{abstract}

Palavras-chave: Projeto OndaTec; UniRec; Estudantes; Educação a distância. 


\section{Introdução}

O artigo ONDATEC: Experiência inovadora com os estudantes do nono ano do ensino fundamental da Rede Municipal de Ensino do Recife, objetiva relatar um Projeto realizado com os estudantes da Prefeitura da Cidade do Recife, denominado OndaTec no ano 2017 em 36 escolas, focalizado na preparação desses jovens estudantes para os exames seletivos da Rede Estadual e Federal utilizando a plataforma da Unidade Virtual de Cursos a Distância da Secretaria de Educação do Recife - UniRec.

Entendemos como relevante e inovadora a experiência, haja vista os resultados obtidos no final de 2017, consideravelmente impactante, tanto em dados estatísticos, quanto em nível social, cultural e porque não dizer econômico, também. O público alvo atingido são os jovens na faixa etária entre 12 e 15 anos, em que o sistema aberto, ou melhor, educação aberta, "encontra-se na adoção de medidas que encorajem a aceitação de alunos de várias condições físicas e sociais [...]", (Santos, 2009, p. 290), em que as barreiras da Educação Fechada, tradicionalmente no uso de suas práticas, não tem mais eco na realidade da RMER, em virtude da qualificação e comprometimento do corpo docente, pautados em princípios norteadores na Política de Ensino (RECIFE, 2014) tomando como base o legado histórico dessa Rede.

Considerando a realidade desses jovens, nativos digitais que, em sua grande maioria o acesso à Tecnologia da Informação e Comunicação é muito precária. Contudo, não existe impedimento para estarem sintonizados com o mundo digital, seja pelo celular em rede wi fi , seja pelo computador da escola., Assim sendo, aproximar a escola dos estudantes com a sedução da linguagem usual desse público, é de suma importância para atraí-los para o processo ensino aprendizagem. Nesse sentido, o projeto ONDATEC foi estruturado em três ambientes, sendo dois deles presenciais, na escola de origem e nos polos (com aulões aos sábados) e o virtual (plataforma UniRec).

Cabe-nos ressaltar, o projeto piloto realizado em 2016 em uma (01) Escola da Rede Municipal de Ensino do Recife - RMER, fruto do trabalho do diretor e docentes da Unidade Escolar que, a partir do resultado positivo, a equipe gestora da Secretaria de Educação em 2017 expandiu o Projeto para as 36 escolas dos Anos Finais da RMER intitulado ONDATEC.

Relataremos a seguir os objetivos, o desenho pedagógico e os resultados obtidos do Projeto, dialogando com os autores sobre a história da educação no Brasil e a contribuição da EaD. Por fim, nas considerações finais enfatizaremos o crescimento dos dados estatísticos no estudo comparativo entre 2016 e 2017 e concluiremos com as 
perspectivas e expectativas para o Ano 2 da experiência no ano em curso/2018.

\section{Objetivo Geral:}

Relatar uma experiência inovadora com os estudantes dos anos finais do ensino fundamental da Rede Municipal de Ensino do Recife.

\section{Objetivos Específicos:}

- Apresentar o desenho pedagógico do Projeto;

- Ressaltar a relevância do Projeto na comparação dos dados estatísticos.

\section{Referencial Teórico}

A Educação formal ao longo dos tempos passou por várias linhas, tendências ou abordagens pedagógicas nos processos de ensino aprendizagem, desde o tradicional ao humanista. Àqueles que defendiam o ensino centrado no dono do saber, o professor, e o aluno era passivo e ficava, apenas, como receptor das informações. A leitura de mundo era algo que no processo de educação formal ficava a cargo da Escola - Família - Igreja que era responsável por transmitir e apresentar à realidade aos alunos. O Ensino nesse modelo tradicional era como instrução, mera transmissão do conhecimento e que cabia, apenas, a Escola à ação da aprendizagem. O ambiente tinha que ser austero para o aluno não se distrair e o professor mantinha distância do aluno. A ênfase era no produto e não no processo Mizukami (1986). Como menciona a autora: "Este tipo de concepção de educação é encontrado em vários momentos da história, permanecendo atualmente sob diferentes formas." (MIZUKAMI, 1986 p. 11)

Contrapondo-se à concepção tradicional, destacaremos três pontos que consideramos relevantes para a discussão: o conhecimento, o ambiente escolar e o papel do professor. Diferentemente do ensino tradicional, a educação na modalidade a distância chega para ficar e fazer a diferença, o conhecimento se dá no processo interativo em que o estudante é protagonista do saber; o ambiente escolar pode ser presencial, semipresencial e a distância e o papel do professor é facilitador do ensino aprendizagem. Nesse sentido, a história da educação a distância no Brasil remonta de mais de um século desde 1904, na perspectiva de "[...] resgatar uma enorme dívida social acumulada ao longo dos séculos." (ALVES, 2009 p. 13). Dessa forma, que o Projeto OndaTec foi pensado utilizando todas as formas e ambientes de aprendizagem, para oportunizar a autonomia e garantir uma educação com qualidade social. 
A política de ensino da RMER contempla em sua dimensão o eixo de Tecnologia na Educação, levando em consideração sua importância que é vanguarda na implementação de políticas para a Rede, no que tange aos projetos didáticos desenvolvidos pelos professores in lócus que conta com a figura do professor multiplicador para subsidiar no incremento dos projetos escolares utilizando as ferramentas tecnológicas. Essas políticas no âmbito municipal acompanham as decisões nacionalmente desde a década de 1990, conforme citação abaixo.

Entre os anos de 1998 e 1999, no âmbito do Prolnfo, foram constituídas novas turmas destinadas à formação de especialistas em informática na educação visando à implantação e ampliação das equipes dos Núcleos de Tecnologia Educacional e à disseminação do uso das tecnologias na escola. À época, o acesso a computadores no meio educacional ainda era limitado, tanto no que se refere ao número de laboratórios instalados nas escolas quanto às possibilidades de aquisição por iniciativa pessoal de professores. Essa oferta reitera a vanguarda da PR em investimentos no campo das tecnologias na educação pública (SETTE; AGUIAR; SETTE, 2000).

Observa-se, ainda, a importância da plataforma UniRec como suporte às aulas das disciplinas de Língua Portuguesa e Matemática, disponibilizando simulados com questões referentes aos anos anteriores do processo seletivo dos exames estadual e federal, a interação com professores/colegas e vídeo aulas. Assim, percebemos que o ambiente virtual aproxima esses jovens e, sobretudo proporciona a autonomia do conhecimento, mediante a organização do tempo de estudo que fica sob sua responsabilidade. A flexibilidade de tempo, espaço e ritmo são avanços da EAD, como afirma o autor.

A EAD brasileira proporcionou um conjunto de inovações por ter possibilitado maior flexibilidade de tempo (quando estudar), espaço (onde estudar) e ritmo (o que estudar e a qual tempo). Outros avanços incluem a incorporação de ferramentas da internet e, em muitos casos, de comunicação via satélite, o que ampliou as possibilidades de disseminação do conteúdo e interação entre os agentes do processo educativo - alunos, docentes e equipes administrativas (GUIMARAES, 2017 p. 33).

Neste contexto, relataremos a seguir o passo a passo da organização dessa experiência inovadora na Prefeitura da Cidade do Recife.

\section{PROCEDIMENTOS METODOLÓGICOS:}

Este curso semipresencial, preparatório para Escolas Técnicas Estaduais de 
Pernambuco - ETE e Instituto Federal de Pernambuco - IFPE, surgiu a partir de uma inquietação do diretor e professores da Escola Florestan Fernandes, com o objetivo de preparar os estudantes do nono ano para ingressarem nas escolas técnicas do estado e no IFPE. Este projeto foi ampliado com o apoio da Gerência de Anos Finais da Secretaria de Educação do Recife.

Inicialmente, esses profissionais, com os recursos que dispunham naquele momento, realizaram atividade extraclasse, aos sábados com simulados de Língua Portuguesa e Matemática.

O diretor da Escola Florestan Fernandes entrou em contato com a coordenação da UniRec e juntos montaram um curso piloto semipresencial, preparatório para exames seletivos com aulas de português e matemática visando ajudar os estudantes a se prepararem para ingresso nessas escolas técnicas. Assim, em julho de 2016 foram cadastrados 46 estudantes.

Os estudantes assistiam às aulas presenciais na própria escola e realizavam atividades na plataforma do curso. Esta plataforma continha vários exercícios de português e matemática, videoaulas do programa Telecurso 2000, exercícios e simulados com questões de provas de anos anteriores. No contraturno, os estudantes participavam de chats com os professores com o objetivo de tirar algumas dúvidas sobre o assunto estudado.

Ao tomar conhecimento do projeto, a Gerência de Anos Finais da Secretaria de Educação do Recife passou a apoiar o projeto que agora contava com 12 escolas da Rede Municipal de Ensino do Recife, 29 professores e 460 estudantes. Nesta plataforma, os estudantes tinham acesso a vídeos explicativos sobre cursos técnicos, orientações para retirar documentos de identidade e outros documentos visando ajudálos a alcançarem seus objetivos de aprendizagem. Dos 460 estudantes, 91 ingressaram nos ETEs.

Em abril de 2017, a Secretaria de Educação do Recife ampliou esse projeto inovador e o nomeou de OndaTec para todos os estudantes das 36 escolas da prefeitura com turmas do 9o ano. A Secretaria de Educação selecionou 40 professores para os aulões aos sábados. Tivemos 1359 estudantes que se inscreveram no projeto. A Secretaria de Educação acrescentou aulões aos sábados, palestras, simulados, apoio à emissão de documentos, formação de grupos de estudo virtual com chat tira-dúvidas, dentre outros incentivos. 


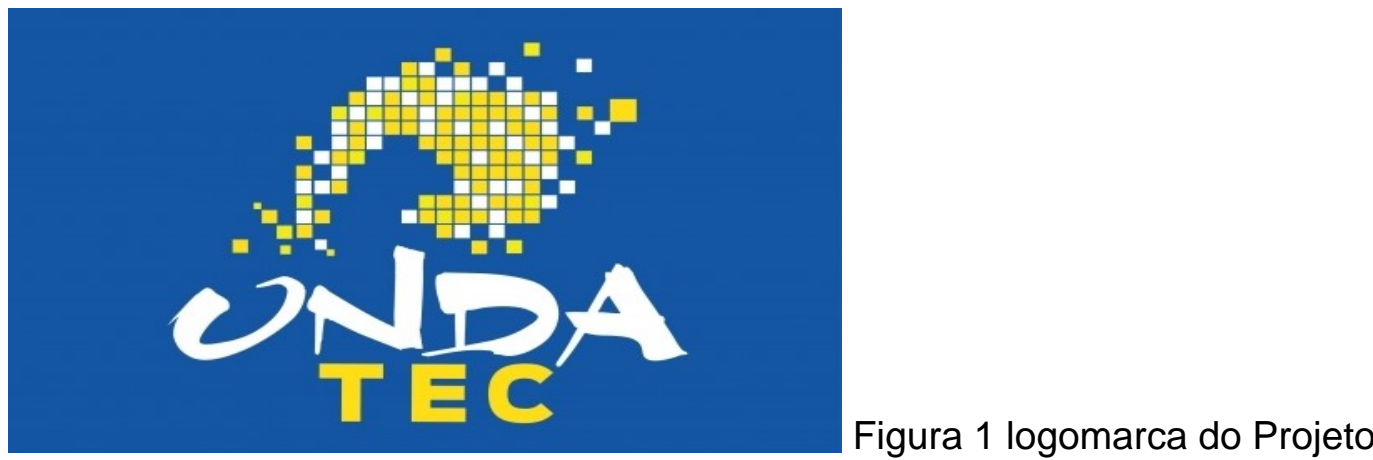

Os estudantes que não tinham interesse em ingressar em um curso técnico também podiam acessar a plataforma visando melhorar o desempenho em matemática e português. Assim, o projeto passa a funcionar como um reforço para as aulas que já são dadas nas escolas.

Além das aulas regulares durante a semana, os estudantes participavam de aulões aos sábados em seis polos de Escolas Técnicas Estaduais do Recife: Almirante Soares Dutra (Santo Amaro); Miguel Batista (Macaxeira); ETEPAM (Espinheiro); Cícero Dias (Boa Viagem); Professor Lucilo Ávila (Caxangá) e José Davi Gil Rodrigues (Jordão), distribuídas pelas zonas Norte, Sul, Oeste e central do Recife.

Além dos recursos e documentos disponíveis na plataforma do curso, os estudantes tiveram a oportunidade de participar de um bate-papo virtual com professores de português e matemática utilizando a ferramenta chat que estava disponível de segunda à sexta-feira das $19 \mathrm{~h}$ às 21 horas.

Enquanto o curso estava em andamento, a equipe administrativa da UniRec fornecia à Secretaria de Educação, aos gestores e coordenadores do projeto, semanalmente, dados estatísticos do acesso dos estudantes em cada documento e notas obtidas nos exercícios e simulados. Com essas informações, a coordenação do projeto direcionava os trabalhos de acompanhamento em unidades onde fosse necessário um suporte técnico, e até mesmo pedagógico, visando ajudar cada estudante a alcançar seus objetivos de estudo.

\section{APRESENTAÇÃO E DISCUSSÃO DOS RESULTADOS}

Neste trabalho, coletamos informações divulgadas pela Secretaria de Educação do Recife e também informações contidas na base de dados da plataforma do curso OndaTec.

Antes da implantação do curso OndaTec, um estudante da RMER ingressar numa 
escola técnica parecia um sonho para a maioria deles, terminavam o ensino médio sem perspectiva profissional. Pois em 2015, tivemos apenas 56 estudantes em toda a RMER que conseguiu ingressar nas ETE ou IFPE. Com o projeto piloto em 2016, este número subiu para 91 estudantes nas ETEs.

Em 2017, a rede de ensino contou com 2.200 estudantes matriculados no nono ano e $61,77 \%$ deles (1.359) se engajaram nos aulões do curso OndaTec e foram distribuídos em 6 polos localizados nos prédios das escolas técnicas do estado, conforme já mencionado nos procedimentos metodológicos.

Como a plataforma do curso estava aberta a todos os estudantes de nono ano da RMER, 2197 estudantes, ou seja, 99,86\% deles solicitaram cadastro na plataforma do curso, porém, somente 995 estudantes acessaram o curso, o que corresponde a 45,22\% dos estudantes cadastrados.

A tabela abaixo mostra o número de visualizações nas ferramentas disponibilizadas no curso entre abril e novembro de 2017.

\begin{tabular}{|l|l|}
\hline \multicolumn{1}{|c|}{ Recursos Tecnológicos Disponiveis } & \multicolumn{1}{c|}{$\begin{array}{c}\text { No de } \\
\text { Visualizaçes }\end{array}$} \\
\hline Ferramenta Livro com Informes sobre o curso. & 455 \\
\hline $\begin{array}{l}\text { Ferramenta Arquivo com instruções para tirar carteira de } \\
\text { identidade. }\end{array}$ & 203 \\
\hline $\begin{array}{l}\text { Ferramenta Livro com informações sobre intercâmbio } \\
\text { oferecido pelas ETE }\end{array}$ & 367 \\
\hline Ferramenta Livro com informações sobre Módulo I & 1850 \\
\hline Ferramenta Livro com informações sobre Módulo II & 1369 \\
\hline Ferramenta Livro com informações sobre Módulo III & 466 \\
\hline Ferramenta Arquivo com videoaula no Módulo I & 1971 \\
\hline Ferramenta Arquivo com videoaula no Módulo II & 1369 \\
\hline Ferramenta Arquivo com videoaula no Módulo III & 466 \\
\hline Ferramenta Questionário para exercícios Módulo I & 4773 \\
\hline Ferramenta Questionário para exercícios Módulo II & 3254 \\
\hline Ferramenta Questionário para exercícios Módulo III & 2164 \\
\hline Ferramenta Questionário para o simulado & 3175 \\
\hline
\end{tabular}

visualizações nas ferramentas do curso

Podemos observar na tabela acima que a ferramenta questionário foi a que teve maior número de visualizações nos três módulos analisados. Considerando que tivemos 995 estudantes participando, concluímos que a ferramenta Questionário foi visualizada mais de 5 vezes pelo mesmo estudante. Esta ferramenta com exercícios e simulados de múltipla escolha e com tentativas ilimitadas possibilitou ao estudante fazer uma autoavaliação do resultado e tentar melhorá-lo a cada nova tentativa. A ferramenta com o simulado teve um diferencial em relação aos exercícios, ele foi cronometrado para o aluno responder em 60 minutos, da mesma forma como as avaliações elaboradas pelo Estado para ingressarem nos ETEs. A ferramenta Chat teve um número considerável de visualizações, possibilitando a interação entre os participantes com o objetivo de 
discutirem dúvidas sobre o assunto estudado.

A ferramenta Arquivo com videoaulas teve 1971 visualizações no Módulo I e foi decrescendo e chegou a 461 visualizações no Módulo III, acreditamos isso tenha ocorrido porque as videoaulas não foram atraentes, foram vídeos antigos do Telecurso 2000 e que estão fora de contexto para a realidade atual dos estudantes. A Gerência de Anos Finais está planejando disponibilizar apenas vídeos produzidos pelos próprios professores de português e matemática para os próximos anos.

A ferramenta Livro com informações sobre o curso e outros documentos foram menos visualizados, pois não havia necessidade de voltar para obter as mesmas informações. Nem todos os alunos visualizaram a ferramenta, pois tais informações já haviam sido dadas nos encontros presenciais.

O OndaTec teve resultado impactante se comparado com anos anteriores onde tivemos 56 estudantes que ingressaram nos ETEs em 2015 e 91 estudantes em 2016. No ano seguinte, com a implantação do OndaTec em 2017, tivemos 312 estudantes ingressando nas escolas técnicas, sendo 233 no ETE, 30 no SESI, 32 no IFPE e 17 na recém inaugurada Escola Técnica Estadual Porto Digital.

O bom desempenho desses estudantes foi comemorado em cerimônia promovida pela Secretaria de Educação do Recife no dia 13 de dezembro de 2017 com a participação do Prefeito do Recife, Secretário de Educação do Estado e Secretário de Educação do Recife.

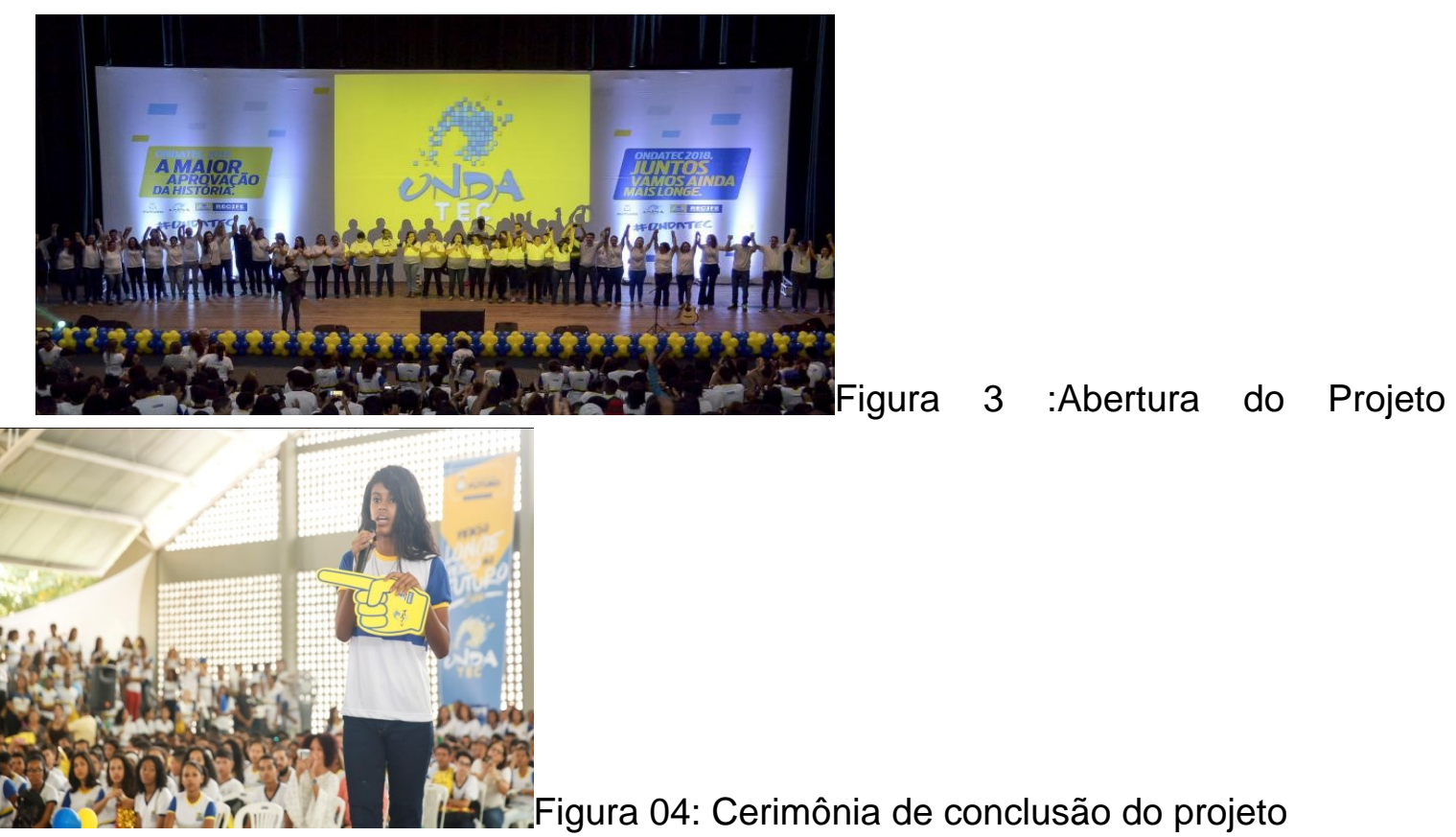




\section{Considerações Finais:}

O principal objetivo deste artigo foi o de chamar a atenção sobre o impacto do projeto OndaTec em ajudar os estudantes da Rede Municipal de Ensino do Recife a ingressarem nos ETEs e IFPE por meio de aulas semipresenciais utilizando a plataforma UniRec.

Enfatizamos o crescimento dos dados estatísticos no estudo comparativo entre 2016 e 2017. O resultado impactante desse projeto se deu graças ao apoio da Secretaria de Educação da Prefeitura do Recife que inicia 2018 já se planejando para ampliar o número de estudantes nos aulões aos sábados.

Vale destacar que a UniRec montou uma sala acústica para gravações de videoaulas com dicas de português e matemática visando ajudar cada estudante a ingressarem nas escolas técnicas estaduais e a estarem mais preparados para os exames seletivos.

Dessa forma, concluímos que, a experiência com o Projeto Onda Tec vislumbra maiores perspectivas de futuro para os estudantes da Rede. Inferimos ainda por meios dos dados analisados, que a experiência inovadora com os estudantes dos anos finais do ensino fundamental da Rede Municipal de Ensino do Recife, objetivo geral deste relato, mudou todo contexto educacional de Recife, sob o ponto de vista da ampliação dos horizontes desses estudantes rumo ao ensino técnico.

\section{Referênciais}

ALMEIDA, Maria Elizabeth Bianconcini (2009) As teorias principais da andragogia e heutagogia, capítulo 15, Educação a Distância: o estado da arte/Fredric Michael Litto, Manuel Marcos Formiga (org.). São Paulo: Pearson Education do Brasil, 2009.

AGUIAR, Jeane. SILVA, Irenice. UGIETTE, Sandra. NERES, Rinaldo (2016) UniRec Unidade Virtual de Cursos a Distância: uma política de acesso ao conhecimento. http://www.abed.org.br/congresso2016/trabalhos/138.pdf

BRASIL. Lei de Diretrizes e Bases da Educação Nacional. L.D.B. № 9394/96, de 20 de dezembro de 1996. Brasília, 1996.

CENSO EAD.BR: relatório analítico da aprendizagem a distância no Brasil 2016, ABED - Associação Brasileira de Educação a Distância; [traduzido por Maria Thereza Moss de Abreu]. Curitiba: InterSaberes, 2017. 2 Mb; PDF. 
RECIFE. Secretaria de Educação. Política de Ensino da Rede Municipal do Recife: subsídios para atualização da organização curricular. / Élia de Fátima Lopes Maçaira (Org.), Katia Marcelina de Souza (Org.), Marcia Maria Del Guerra (Org.). - 2 ed. -Recife: Secretaria de Educação, 2014. (v. 1).

RECIFE (PE) Prefeitura. Acompanhamento e avaliação educacionais: uma nova possibilidade de organização. Cadernos da Educação Municipal, Recife, v.1, 2008.

. Plano municipal de educação: retrospectiva: bases legais. Recife, 2005.

Proposta pedagógica da rede municipal de ensino do Recife: construindo competências: versão preliminar. Recife, 2002. Mimeografado.

Portal da Educação. Prefeitura do Recife.

https://www.google.com.br/search?q=porta+da+educa\%C3\%A7\%C3\%A3o+recife\&oq

SILVA, Adriana e NERES, Rinaldo (2015) Unidade Virtual de cursos a Distância da Secretaria de Educação do Recife: formação continuada para redes de aprendizagens

https://drive.google.com/file/d/OB8RuN4liyxxYmswSIFLMORZZDR6cWJjazcyT2d1aUwxN 21R/view?usp=sharing

SETTE, Sonia Schechtman. ANGEIRAS, Maria de Fátima Duarte. BRITO, Maria Cleoneide Adolfo. NERES, Rinaldo da Silva. A Educação a Distância Renovada como Instrumento de Formação e de Gestão http://escoladegestores.mec.gov.br/site/8biblioteca/pdf/distancia_renovada.pdf 